\title{
Điều kiện hình thành và phát triển mô hình liên kết nghiên cứu khoa học với sản xuất và đào tạo ở Viện Hàn lâm Khoa học và Công nghệ Việt Nam
}

\author{
Đào Thanh Trường ${ }^{1, *}$, Phạm Tuấn Huy ${ }^{2}$ \\ ${ }^{1}$ Truòng Đại học Khoa học Xã hội và Nhân văn, ĐHQGHN, \\ 336 Nguyến Trãi, Thanh Xuân, Hà Nội, Việt Nam \\ ${ }^{2}$ Viện Hàn lâm Khoa học và Công nghệ Việt Nam, 18 Hoàng Quốc Việt, Cà̀u Giáy, Hà Nội, Việt Nam
}

Nhận ngày 9 tháng 8 năm 2017

Chỉnh sửa ngày 14 tháng 9 năm 2017; Chấp nhận đăng ngày 28 tháng 9 năm 2017

\begin{abstract}
Tóm tắt: Khi mới thành lập, Viện Khoa học Việt Nam (nay là Viện Hàn lâm Khoa học và Công nghệ Việt Nam) hoạt động theo mô hình Viện Hàn lâm Khoa học Liên Xô nên có sự phân li giữa nghiên cứu khoa học với sản xuất và đào tạo. Trong 40 năm qua Viện đã từng bước khắc phục sự phân ly này, nhiều mô hình liên kết khoa học với sản xuất và đào tạo đã được thực hiện.

Tuy nhiên, phát triển Viện Hàn lâm phù hợp với tình hình hội nhập quốc tế cần những điều kiện để hình thành và phát triển các mô hình liên kết giữa nghiên cứu khoa học với sản xuất và đào tạo. Đó là những điều kiện quản lý vĩ mô và nỗ lực của Viện Hàn lâm cũng như các Viện chuyên ngành.
\end{abstract}

Từ khóa: Điều kiện, liên kết khoa học - sản xuất - đào tạo.

\section{1. Đặt vấn đề}

Nghị quyết 26/NQ-TW của Bộ Chính trị Đảng Cộng sản Việt Nam về chính sách khoa học và công nghệ (KH\&CN) đưa ra chủ trương "nhất thể hóa khoa học và giáo dục" cùng với "nhất thể hóa khoa học và sản xuất". Đây là chủ trương gắn nghiên cứu khoa học với đào tạo và sản xuất được Đảng đề xuất năm 1991 [1].

Do được thành lập theo mô hình Viện Hàn lâm của các nước Xã hội chủ nghĩa nên hoạt động nghiên cứu khoa học của Viện Hàn lâm Khoa học và Công nghệ Việt Nam (Viện Hàn

\footnotetext{
*Tác giả liên hệ. ĐT.: 84-912721843.

Email: pthuy@vast.vn

https://doi.org/10.25073/2588-1116/vnupam.4113
}

lâm) tách rời khỏi hoạt động đào tạo và sản xuất. Trong khi đó các tổ chức $\mathrm{KH} \& \mathrm{CN}$ trên thế giới hoạt động nghiên cứu khoa học được liên kết chặt chẽ với hoạt động sản xuất và đào tạo. Vì vậy, để phù hợp với chức năng cơ bản của các Viện $K H \& C N$ trên thế giới, Viện Hàn lâm cần xây dựng và hoàn thiện mô hình liên kết nghiên cứu khoa học với đào tạo và sản xuất.

Trong suốt quá trình trên 40 năm phát triển, Viện Hàn lâm luôn nỗ lực khắc phục sự phân ly nghiên cứu khoa học với hoạt động sản xuất và đào tạo, nhiều mô hình liên kết khoa học với sản xuất và liên kết khoa học với đào tạo đã được thực hiện. Cùng với sự phát triển của mình Viện Hàn lâm đã tái cấu trúc để hoàn thiện chức năng đào tạo và sản xuất, đến nay mô hình liên kết khoa học - đào tạo đã được 
hoàn thiện ở cấp Viện Hàn lâm, các Viện trực thuộc cần nỗ lực hơn nữa để cùng một lúc thực hiện cả chức năng nghiên cứu khoa học lẫn chức năng đào tạo. Mô hình liên kết khoa học sản xuất đã tiến triển qua 3 giai đoạn, giai đoạn hiện nay phát triển chậm hơn do liên kết khoa học - sản xuất mang tính rủi ro cao. Vì vậy cần xác lập điều kiện cần và đủ để xây dựng, phát triển mô hình liên kết nghiên cứu khoa học với hoạt động sản xuất và đào tạo theo hướng tự chủ, tự chịu trách nhiệm ở Viện Hàn lâm trong giai đoạn tới.

\section{2. Điều kiện cần cho sự hình thành và phát triển liên kết nghiên cứu khoa học với sản xuất và đào tạo tại Viện Hàn lâm}

Để hình thành và phát triển liên kết nghiên cứu khoa học với sản xuất và đào tạo tại Viện Hàn lâm cần có các điều kiện về kinh tế thị trường cùng với các chính sách vĩ mô của Nhà nước về: thực hiện nhiệm vụ khoa học; tài chính, vốn, tín dụng, thuế; các chính sách về tổ chức nhân lực và hợp tác quốc tế.

\section{1. Điều kiện chung của nền kinh tế thị trương}

Trước khi Quyết định 175/CP năm 1981 của Chính phủ được ban hành, các Viện nghiên cứu và triển khai $(\mathrm{R} \& \mathrm{D})$ được Nhà nước chỉ đạo trong công tác nghiên cứu, hoạt động nghiên cứu khoa học được tách rời hoạt động sản xuất, mọi quan hệ hợp đồng ngang giữa các Viện với nhau hoặc giữa các Viện và doanh nghiệp đều bị cấm đoán. Các sản phẩm $R \& D$ chỉ được "phân phối" theo con đường hành chính. Quyết định 175/CP ban hành cho phép các Viện R\&D ký kết hợp đồng với nhau để hợp tác nghiên cứu; họ cũng được ký hợp đồng với các doanh nghiệp để áp dụng kết quả nghiên cứu vào sản xuất. Đó là bước chuyển đổi hoàn toàn phù hợp với xu thế chuyển đổi thể chế kinh tế, từ hệ thống kinh tế do nhà nước độc tôn chỉ huy sang hệ thống kinh tế thị trường [2].

Trong những năm qua thị trường của nước ta đang trong quá trình hình thành và phát triển nên còn ở trình độ thấp. Dung lượng thị trường nhỏ hẹp, cơ cấu và các yếu tố kinh tế thị trường hình thành chưa đầy đủ. Chưa có thị trường sức lao động theo đúng nghĩa, thị trường tài chính, thị trường bất động sản, thị trường $\mathrm{KH} \& \mathrm{CN}$ còn sơ khai, phát triển chậm. Vì vậy liên kết giữa nghiên cứu khoa học với sản xuất và đào tạo chưa được phát huy. Qua đó ta thấy kinh tế thị trường chi phối sự hình thành và phát triển mô hình liên kết giữa nghiên cứu khoa học với sản xuất và đào tạo.

Để hình thành và phát triển mô hình liên kết giữa nghiên cứu khoa học với sản xuất và đào tạo ở nước ta cần có nền kinh tế thị trường thực sự, các quy luật cơ bản của kinh tế thị trường phải được tôn trọng, các loại thị trường cần được phát triển đồng bộ.

Trong bài phát biểu tại Đại hội KH\&CN quốc gia năm 1985, Thủ tướng Trung quốc Triệu Tử Dương đã nói: "Kinh nghiệm của 30 năm qua chỉ ra rằng, do mối quan hệ hàng hóa vốn tồn tại trong một nền kinh tế, nên chúng ta không thể đạt được kết quả mong muốn trong bất kỳ tổ chức nào có liên quan tới kinh tế nếu chúng ta bỏ qua quan hệ hàng tiền, coi nhẹ quy luật giá trị và vai trò của các đòn bẩy kinh tê.... để nối các Viện với các đơn vị sản xuất trong một sự nghiệp chung chúng ta phải áp dụng một loạt các biện pháp kinh tế gắn họ với mối quan hệ lời lãi,.."[3].

Trong kinh tế thị trường, các doanh nghiệp chỉ có thể đứng vững trong cạnh tranh nếu thường xuyên đồi mới công nghệ để hạ chi phí, nâng cao chất lượng sản phẩm. Muốn vậy, phải đẩy mạnh công tác nghiên cứu và ứng dụng các thành tựu mới của cuộc cách mạng $\mathrm{KH} \& \mathrm{CN}$ vào quá trình sản xuất và lưu thông hàng hóa. So với thế giới, trình độ công nghệ sản xuất của Việt Nam còn thấp kém, không đồng bộ, do đó, khả năng cạnh tranh của hàng hóa nước ta so với hàng hóa nước ngoài trên cả thị trường nội địa và thế giới còn kém. Bởi vậy, để phát triển kinh tế hàng hóa, vận dụng quy luật "thị trường kéo" chúng ta phải đẩy mạnh liên kết giữa nghiên cứu khoa học với sản xuất và đào tạo.

Để khẳng định vai trò của Nhà nước trong nền kinh tế thị trường, trước hết cần xây dựng 
nền kinh tế thị trường thực sự đi kèm với nó là ban hành những chính sách vĩ mô thúc đẩy thị trường $\mathrm{KH} \& \mathrm{CN}$ phát triển đồng thời giữ trong sạch thị trường mua - bán.

\subsection{Chính sách vĩ mô thục hiện nhiệm vu khoa hoc}

Ngay từ khâu xây dựng chính sách KH\&CN Nhà nước cần huy động sự tham gia của các nhà khoa học và doanh nghiệp để chính sách có tính khả thi cao đồng thời $\mathrm{KH} \& \mathrm{CN}$ có điều kiện phục vụ người dân và doanh nghiệp.

Nhà nước cần có chính sách ưu tiên phát triển những mũi nhọn $\mathrm{KH} \& \mathrm{CN}$ trong từng thời kỳ và có chính sách thích hợp khuyến khích doanh nghiệp cùng các thành phần kinh tế đầu tư cho hoạt động nghiên cứu, đào tạo và triển khai công nghệ. Công bố và điều chỉnh các chính sách ưu tiên, khuyến khích mở các ngành đào tạo mới, mở các hướng nghiên cứu mới, khuyến khích vừa học vừa làm.

Xác định vai trò của Nhà nước trong hoạt động KH\&CN là thực hiện quản lý Nhà nước, không trực tiếp tham gia hoạt động KH\&CN.

Nhà nước cần có chính sách trao quyền tự chủ cao nhất cho các tổ chức KH\&CN công lập trong việc lựa chọn vấn đề nghiên cứu, phương pháp và phạm vi nghiên cứu.

Nhà nước ban hành chính sách thúc đẩy liên kết hoạt động nghiên cứu khoa học và đào tạo với sản xuất ở các tổ chức khoa học công lập và các trường đại học, bao gồm các chính sách sau:

- Chính sách tái tạo mối liên kết giữa khoa học với sản xuất, tạo lập liên hệ chặt chẽ giữa các Viện công nghệ với sản xuất, ban hành chính sách thúc đầy "thị trường kéo". Hiện nay hầu hết hoạt động triển khai kết quả nghiên cứu vào sản xuất đều xuất phát từ chính sách "KH\&CN đẩy", trong tương lai cần có chính sách giảm thiểu hoạt động này và tăng cường hoạt động KH\&CN theo chính sách "thị trường kéo".

- Chính sách gắn hoạt động $R \& D$ với đào tạo trong các Viện và các Trường trong cơ chế tự chủ.
- Chính sách đối với hoạt động R\&D của doanh nghiệp trong cơ chế thị trường [4].

2.3. Chính sách vĩ mô về tài chính, vốn, tín dụng, thuế...

Nhà nước cần ban hành chính sách vận dụng cơ chế thị trường và quản lý $\mathrm{KH} \& \mathrm{CN}$, thúc đẩy thị trường $\mathrm{KH \& CN}$, để thị trường vận động theo quan hệ cung - cầu của kinh tế thị trường.

Cần có chính sách thúc đẩy thành lập các quỹ $\mathrm{KH} \& \mathrm{CN}$, tài trợ cho hoạt động KH\&CN, đặc biệt khuyến khích thành lập các quỹ do doanh nghiệp thành lập, quản lý và điều hành. Thành lập quỹ đầu tư mạo hiểm hỗ trợ doanh nghiệp KH\&CN khởi nghiệp. Các chính sách về tài chính đối với hoạt động $\mathrm{KH} \& \mathrm{CN}$ cần tính đến tính mới và tính rủi ro của hoạt động thương mại hóa kết quả nghiên cứu. Thất thoát tài chính khi triển khai kết quả nghiên cứu vào sản xuất là điều các nhà hoạch định chính sách tài chính cho liên kết hoạt động $\mathrm{KH} \& \mathrm{CN}$ với sản xuất cần tính đến.

Chính sách tài chính đối với hoạt động KH\&CN: quản lý kiểm soát chi tiêu tài chính theo cơ chế gắn với kết quả nghiên cứu, sản phẩm KH\&CN và hiệu quả kinh tế. Thực hiện cơ chế cạnh tranh trong cấp phát và tài trợ kinh phí hoạt động KH\&CN sử dụng ngân sách Nhà nước.

Ưu tiên bố trí ngân sách Nhà nước cho hoạt động $\mathrm{KH \& CN}$, có chính sách huy động tối đa các nguồn lực đầu tư cho hoạt động $\mathrm{KH} \& \mathrm{CN}$ đặc biệt từ khối doanh nghiệp.

Nhà nước cần đầu tư đủ lớn, đáp ứng yêu cầu về nguồn tài chính đối với các hướng KH\&CN mũi nhọn, tránh đầu tư dàn trải, lãng phí nguồn lực.

Cần có chính sách hỗ trợ tín dụng, miễn giảm thuế, thúc đẩy doanh nghiệp $\mathrm{KH} \& \mathrm{CN}$ phát triển, đặc biệt cần có chính sách tài chính hỗ trợ và thúc đầy thành lập các doanh nghiệp khởi nghiệp trong lĩnh

Trong số các chính sách vĩ mô, để thúc đẩy liên kết khoa học và sản xuất quan trọng nhất là 
chính sách thuế. Để khuyến khích doanh nghiệp đổi mới công nghệ, tạo ra sản phẩm mới, vật liệu mới cần có chính sách giảm thuế xuất đối với những mặt hàng này và tăng thuế xuất đối với những sản phẩm cùng loại sản xuất theo công nghệ cũ, lạc hậu. Mục đích của chính sách này là khuyến khích, thúc đẩy những doanh nghiệp đổi mới công nghệ đồng thời trừng phạt doanh nghiệp sử dụng công nghệ cũ, lạc hậu, có tác động xấu đến môi trường.

\subsection{Chính sách vĩ mô về tổ chức và nhân lực}

Nhà nước cần có chính sách thu hút nhân lực có trình độ cao trong đó có việt kiều và các nhà khoa học nước ngoài tham gia hoạt động KH\&CN, bao gồm chính sách ưu đãi về thu nhập, điều kiện và môi trường làm việc.

Cải cách cơ chế quản lý các tổ chức KH\&CN công lập, trao quyền tự chủ tối đa về tổ chức bộ máy và quản lý, sử dụng nhân lực, quản lý và phân phối thu nhập cho các tổ chức này.

Tăng cường các biện pháp khuyến khích, hỗ trợ thành lập doanh nghiệp spin-off trong các tổ chức KH\&CN. Có chính sách để nhân lực $\mathrm{KH} \& \mathrm{CN}$ có trình độ cao thực hiện kiêm nhiệm tại các tổ chức KH\&CN, doanh nghiệp và trường đại học hoặc Học viện. Đề nghị bỏ quy định công chức không được làm giám đốc doanh nghiệp đối với Lãnh đạo các Viện công nghệ để Lãnh đạo các Viện này có khả năng kiêm nhiệm giám đốc doanh nghiệp Spin-off.

Ban hành chính sách để tái cơ cấu các tổ chức $\mathrm{KH \& CN}$ và các trường đại học nghiên cứu, góp phần tạo lập liên kết nghiên cứu khoa học với đào tạo và sản xuất tại các đơn vị này.

Có chính sách cho phép các doanh nghiệp tự thành lập mới các đơn vị R\&D hoặc thu nhận một đơn vị "spin-out" hoặc đơn vị vệ tinh "spinoff" của Viện về đơn vị sản xuất để phục vụ chiến lược phát triển của doanh nghiệp, nếu không triển khai tiếp hoạt động R\&D tại doanh nghiệp các đơn vị này có thể quay lại Viện nghiên cứu.

Thời gian vừa qua Chính phủ đã cho phép thành lập trường đại học và Học viện trong
Viện Hàn lâm, chính sách này đã thúc đẩy Viện Hàn lâm tự hoàn thiện mình để cùng một lúc thực hiện cả chức năng nghiên cứu khoa học lẫn chức năng đào tạo.

Nhà nước cần có chính sách thúc đẩy thị trường nhân lực $\mathrm{KH} \& \mathrm{CN}$, ban hành chính sách bỏ biên chế đối với cán bộ khoa học để có thể vô hiệu hóa hàng loạt văn bản pháp quy bất hợp lý. Bỏ biên chế cơ hữu sẽ giúp cho thị trường điều khiển luồng di động nhân lực $\mathrm{KH} \& \mathrm{CN}$ đồng thời chủ động điều chỉnh di động nhân lực KH\&CN không kèm di cư.

Tóm lại, chính sách vĩ mô về tổ chức để thúc đẩy liên kết khoa học với đào tạo và sản xuất cần tôn trọng khả năng tự điều chỉnh của tổ chức KH\&CN, có chính sách tạo điều kiện để các tổ chức này tự điều chỉnh theo hướng đa dạng hóa cấu trúc.

\subsection{Chinh sách vĩ mô về hợp tác quốc tế}

Có hai bài học hết sức quan trọng từ kinh nghiệm quốc tế để giải quyết sự phân li giữa khoa học và đào tạo đó là công nhận những tiêu chuẩn chung về tri thức được đào tạo khi hội nhập quốc tế và tạo lập tính tự chủ cao cho các nhà khoa học [5].

Trong điều kiện nước ta đang ở xuất phát điểm thấp về $K H \& C N$ so với thế giới, cần có chính sách hợp tác quốc tế về KH\&CN để tận dụng nguồn vốn và khắc phục sự phân li giữa nghiên cứu với đào tạo và sản xuất.

Vừa qua Chính phủ đã cho phép Bộ $\mathrm{KH \& CN}$ thành lập Viện Công nghệ công nghiệp Việt Nam - Hàn quốc (VKIT) và ban hành quy chế hoạt động đặc biệt cho đơn vị này là minh chứng cho chính sách hợp tác quốc tế để phát triển tiềm lực $\mathrm{KH} \& \mathrm{CN}$ của đất nước.

Các chính sách hợp tác quốc tế thúc đẩy sự hình thành và phát triển liên kết nghiên cứu khoa học với sản xuất và đào tạo cần tính đến tính truyền thống, tính kế thừa và quan hệ quốc tế đã được các tổ chức KH\&CN xác lập.

Cần có chính sách để nhập khẩu công nghệ và "Việt hóa" cho phù hợp với Việt Nam, phối hợp với doanh nghiệp trong nước để tìm kiếm, 
nhập khẩu, nghiên cứu phát triển cho phù hợp nhu cầu trong nước và chuyển giao công nghệ.

\section{3. Điều kiện đủ cho sự hình thành và phát triển liên kết nghiên cứu khoa học với sản xuất và đào tạo tại Viện Hàn lâm}

Ngoài các điều kiện cần là các chính sách vĩ mô nêu trên, để hình thành và phát triển liên kết nghiên cứu khoa học với sản xuất và đào tạo còn cần nỗ lực của Viện Hàn lâm và các Viện chuyên ngành

3.1. Điều kiện về tổ chức thúc đẩy sư hình thành và phát triển liên kết nghiên cứu khoa hoc với sản xuất và đào tạo

Để thúc đẩy sự hình thành và phát triển liên kết nghiên cứu khoa học với sản xuất và đào tạo cần cho phép các tổ chức $K H \& C N$ quyền tự điều chỉnh, thay đổi cấu trúc của đơn vị cho phù hợp với biến động của môi trường đáp ứng sự phát triển của tổ chức. Nghị định số 54/2016/NĐ-CP quy định cơ chế tự chủ của tổ chức $\mathrm{KH} \& \mathrm{CN}$ công lập, mới trao quyền này cho các tổ chức tự đảm bảo chi thường xuyên [6].

Cấu trúc "ma trận" là loại hình tổ chức tích hợp cấu trúc chức năng và cấu trúc dự án. Sự tích hợp đó thể hiện sự kết hợp hài hoà của tổ chức hình thức và phi hình thức, là bước phát triển cao của tổ chức hữu cơ. Cấu trúc chức năng thường gặp trong các tổ chức máy móc như các Vụ ở các Bộ, các Phòng nghiên cứu ở các Viện, các Phân xưởng trong nhà máy ... Còn cấu trúc dự án là loại tổ chức hữu cơ cũng có thể xem như tổ chức phi hình thức, cấu trúc này là tập hợp một số nhân lực thực hiện một dự án, một chương trình, một công việc ,... nằm ngoài khu vực chức năng. Tồ hợp hai cấu trúc đó lại hình thành nên cấu trúc ma trận [7].

Để đảm bảo cho sự hình thành và phát triển liên kết nghiên cứu khoa học với sản xuất và đào tạo, Viện Hàn lâm cần chuyển từ cấu trúc "chức năng" sang cấu trúc "ma trận" (chuyển từ lý thuyết cơ học sang lý thuyết hữu cơ). Biểu hiện đặc trưng của cấu trúc "ma trận" là đa dạng hóa cấu trúc tổ chức $\mathrm{KH} \& \mathrm{CN}$.

3.2. Điều kiện về quản lý thúc đẩy sư hình thành và phát triển liên kết nghiên cưu khoa hoc với sản xuất và đào tạo

Chuyển từ hoạt động theo mô hình hàn lâm của các nước Xã hội chủ nghĩa sang hoạt động theo mô hình liên kết nghiên cứu với đào tạo và sản xuất cần chuyển đổi mô hình hành chính hóa trong quản lý khoa học. Bộ máy quản lý khoa học đang có nhiệm vụ quản lý và phân bổ kinh phí cho hoạt động nghiên cứu do Nhà nước cấp nay quản lý cả lĩnh vực sản xuất và đào tạo cần có sự chuyển đổi phù hợp.

Vai trò của quản lý khoa học trong việc xây dựng và phát triển mô hình liên kết nghiên cứu, đào tạo, sản xuất tại Viện Hàn lâm là hết sức quan trọng, nhiệm vụ xây dựng bộ máy quản lý khoa học có năng lực và hiệu quả trong thời gian tới là hết sức cấp thiết.

Để xây dựng bộ máy quản lý khoa học hiệu quả cần bỏ bớt các đầu mối trung gian, phân cấp quản lý $\mathrm{KH} \& \mathrm{CN}$, tách chức năng quản lý Nhà nước và quản lý hoạt động KH\&CN đồng thời dân chủ hóa hoạt động KH\&CN. Đơn giản hóa thủ tục hành chính, đưa hoạt động KH\&CN tiếp cận có hiệu quả với hoạt động sản xuât, phát triển kinh tế - xã hội.

Xây dựng cơ chế phù hợp để thúc đẩy liên kết hoạt động khoa học và đào tạo với doanh nghiệp, quản lý tài sản trí tuệ, thương mại hóa công nghệ. Khuyến khích các chuyên gia công nghệ nghiên cứu, giải quyết các vấn đề do thị trường và doanh nghiệp yêu cầu.

Đề xuất quy chế và triển khai chương trình hỗ trợ đổi mới sáng tạo nhằm gắn kết nghiên cứu và đào tạo với sản xuất

Viện Hàn lâm cần đẩy mạnh hoạt động xúc tiến, thương mại hóa công nghệ bao gồm các hoạt động khảo sát nhu cầu của doanh nghiệp, thị trường; hoạt động giới thiệu và quảng bá công nghệ, tạo điều kiện để các doanh nghiệp hợp tác với khối Viện công nghệ. 
Thành lập trung tâm khởi nghiệp trong Viện Hàn lâm với các mục đích: hỗ trợ hoạt động khởi nghiệp cho sinh viên, học viên cao học và nghiên cứu sinh cũng như cán bộ khoa học; mở các khóa học về thương mại hóa kết quả nghiên cứu, tạo lập quan hệ với các nhà đầu tư mạo hiểm, với cộng đồng doanh nghiệp... sẽ góp phần xây dựng bộ máy quản lý khoa học có hiệu quả.

Để nâng cao hiệu quả quản lý của bộ máy, chất lượng chuyên viên và cán bộ quản lý là hết sức quan trọng. Các chuyên viên cần nỗ lực hơn để nắm bắt trình độ công nghệ trong nước và của khu vực. Hiểu biết về kinh tế, tiếp thị của đội ngũ chuyên viên còn hạn chế do hậu quả của sự phân li khoa học - sản xuất để lại. Để xây dựng và phát triển mô hình liên kết nghiên cứu, đào tạo, sản xuất tại Viện Hàn lâm cần nâng cao chất lượng đội ngũ chuyên viên thông qua rèn luyện nâng cao năng lực công nghệ, bổ xung các hiểu biết về kinh tế thị trường và tiếp thị, có tinh thần triển khai kết quả nghiên cứu vào sản xuất, phối hợp nghiên cứu với đào tạo.

\subsection{Vai trò nguời lãnh đạo thúc đẩy sụ hình thành và phát triển liên kết nghiên cứu khoa hoc với sản xuất và đào tạo}

Ngoài quyền tự chủ, năng lực tự chủ còn cần đến tinh thần tự chủ để hình thành và phát triển mô hình liên kết nghiên cứu với đào tạo và sản xuất cho Viện Hàn lâm.

Tinh thần tự chủ phụ thuộc tố chất Nhà lãnh đạo khoa học. Tầm nhìn và sức lôi cuốn quyết định tố chất của Nhà lãnh đạo khoa học. Chỉ những nhà lãnh đạo khoa học có tầm nhìn mới nhận biết tầm quan trọng của mô hình liên kết nghiên cứu với đào tạo và sản xuất ở Viện Hàn lâm để có thể xây dựng và đưa mô hình này vào hoạt động thực tế tại đơn vị. Bản lĩnh cùng những tố chất đạo đức giúp nhà lãnh đạo khoa học tạo nên sự đồng thuận và sức lôi cuốn mạnh mẽ các đồng nghiệp thực hiện chiến lược liên kết nghiên cứu khoa học với sản xuất và đào tạo đã đề ra.

Ngoài chuyên môn sâu, nhà lãnh đạo khoa học cũng cần am hiểu các lĩnh vực chuyên môn rộng của Viện, của ngành để điều hòa, phối hợp và thúc đẩy các lĩnh vực này phát triển, bổ trợ cho các hướng mũi nhọn của Viện, đồng thời phối hợp, cộng tác với những Viện liên quan [8].

Cùng với những hiểu biết sâu sắc về lý thuyết, nhà lãnh đạo khoa học cần có kỹ năng thực hành trong lĩnh vực chuyên môn sâu của mình đề gắn nghiên cứu với sản xuất. Liên kết khoa học với sản xuất ở Viện Hàn lâm phát triển mạnh từ những năm 1990 , thành công và thất bại của mô hình này cần tổng kết, rút kinh nghiệm triển khai trong giai đoạn tới.

Vì vậy, để xây dựng và phát triển mô hình liên kết nghiên cứu, đào tạo, sản xuất tại Viện Hàn lâm, Lãnh đạo Viện Hàn lâm cũng như lãnh đạo các Viện chuyên ngành cần xác lập tinh thần tự chủ. Chính họ là những người góp phần có tính chất quyết định đến sự thành công hay thât bại của quá trình xây dựng và phát triển mô hình liên kết nghiên cứu với đào tạo và sản xuất tại Viện Hàn lâm.

3.4. Môi trường làm việc thúc đẩy su hình thành và phát triển liên kết nghiên cứu khoa hoc với sản xuất và đào tạo

Cần tạo lập môi trường làm việc dân chủ, để liên kết khoa học với sản xuất cần tạo môi trường nghiên cứu gắn kết với hoạt động khởi nghiệp cũng như thành lập các spin-off trong Viện, kinh nghiệm thành lập văn phòng khởi nghiệp của Đại học Quốc gia Singapore (NUS) là kinh nghiệm quý để liên kết khoa học với sản xuất.

Môi trường làm việc gắn nghiên cứu với đào tạo ngay tại các phòng, trung tâm thuộc Viện cần được coi như bộ môn trong trường, các Viện cần có môi trường làm việc như các khoa của Học viện để phát triển liên kết khoa học và đào tạo. Cán bộ khoa học của Viện ngoài hoạt động nghiên cứu còn tham gia hoạt động đào tạo, xóa bỏ ranh giới nghiên cứu viên và giảng viên.

Để hình thành và phát triển liên kết khoa học - sản xuất các Viện công nghệ cần được tăng cường năng lực về nguồn cán bộ công 
nghệ và cần được đầu tư tới ngưỡng về máy móc, trang thiết bị nghiên cứu, phòng thí nghiệm hiện đại, ít nhất ngang tầm khu vực trong từng lĩnh vực nghiên cứu.

Quyền và năng lực tự chủ sẽ tạo lập môi trường làm việc cần thiết cho sự hình thành và phát triển mô hình liên kết nghiên cứu - đào tạo và sản xuất cho Viện Hàn lâm. Trao quyền tự chủ cho các phòng, khoa, trung tâm trực thuộc các Viện và Học viện sẽ thúc đẩy quá trình chuyển đổi hoạt động của các đơn vị này.

Môi trường làm việc thuận lợi là điều kiện cần thiết để tạo cơ chế phát huy năng lực sáng tạo của đội ngũ cán bộ KH\&CN trong Viện Hàn lâm, góp phần bồi dưỡng và đào tạo nhân tài trong lĩnh vực $\mathrm{KH} \& \mathrm{CN}$.

3.5. Co sở ha tầng thúc đẩy sự hình thành và phát triển liên kết nghiên cứu khoa học với sản xuất và đào tạo

Cần tăng cường số lượng các phòng thí nghiệm trọng điểm quốc gia cho các Viện chuyên ngành thuộc Viện Hàn lâm. Tăng cường năng lực cho các Viện chuyên ngành cũng là tăng cường năng lực cho các khoa thuộc Học viện $\mathrm{KH} \& \mathrm{CN}$ đề tăng cường liên kết nghiên cứu khoa học với sản xuất và đào tạo tại Viện Hàn lâm. Viện hiện có $4 / 16$ phòng thí nghiệm trọng điểm quốc gia/cả nước chưa đáp ứng được yêu cầu của Viện đa ngành đa lĩnh vực như Viện Hàn lâm.

Viện Hàn lâm cần đầu tư xây dựng, mở rộng và phát triển khu thử nghiệm, ươm tạo công nghệ. Ngoài việc đầu tư, nâng cấp các phòng thí nghiệm, Viện cần đầu tư nâng cấp Trung tâm thông tin tư liệu để cung cấp nguồn lực thông tin, phục vụ hoạt động nghiên cứu, đào tạo và sản xuất; tạo lập quyền khai thác có hiệu quả các kết quả nghiên cứu được lưu trữ và phát triển hệ thống thông tin tư liệu.

Viện cũng cần được đầu tư về tài chính để thành lập quỹ triển khai công nghệ dưới dạng quỹ đầu tư mạo hiểm để triển khai công nghệ, gắn nghiên cứu với sản xuất và thương mại hóa kết quả nghiên cứu. Nguồn kinh phí này còn có tác dụng gián tiếp để nâng cao chất lượng đào tạo của Viện.

3.6. Nhân lực Khoa học và Công nghệ thúc đẩy sụ hình thành và phát triển liên kết nghiên cưu khoa hoc vói sản xuất và đào tạo

Cán bộ khoa học tại các Viện chuyên nghành cần nỗ lực hơn để đạt đến trình độ công nghệ của khu vực góp phần xây dựng và phát triển mô hình liên kết nghiên cứu, đào tạo, sản xuất tại Viện Hàn lâm. Cần nâng cao tinh thần tự chủ của đội ngũ cán bộ khoa học thông qua rèn luyện bồi dưỡng năng lực công nghệ, bổ xung các hiểu biết về kinh tế thị trường và tiếp thị, có tinh thần triển khai kết quả nghiên cứu vào sản xuất và phối hợp nghiên cứu với đào tạo.

Để phát huy tối đa nguồn nhân lực KH\&CN trong Viện Hàn lâm, cần xóa bỏ chế độ biên chế cơ hữu đối với nhân lực KH\&CN trong Viện, tạo điều kiện tập trung nguồn nhân lực có trình độ cao cho các hướng phát triển được ưu tiên. Nghị định 54/2016/NĐ-CP ngày 14/6/2016 quy định cơ chế tự chủ của tổ chức KH\&CN công lập do Chính phủ ban hành đã xóa bỏ quỹ lương, đưa tiền lương của cán bộ khoa học vào nhiệm vụ thường xuyên theo chức năng, điều này sẽ tạo điều kiện để Viện Hàn lâm bỏ biên chế cơ hữu trong thời gian tới.

Bỏ biên chế cơ hữu trong Viện sẽ khuyến khích di động xã hội đối với nhân lực KH\&CN có trình độ cao trong và ngoài Viện Hàn lâm, thúc đẩy di động không di cư nguồn lực KH\&CN tạo điều kiện kiên kết nghiên cứu với đào tạo và sản xuất ở Viện Hàn lâm.

\section{Kết luận}

Liên kết giữa hoạt động khoa học với đào tạo và sản xuất là nhu cầu tự thân của các tổ chức khoa học. Hình thành và phát triển mối liên kết này trong tổ chức khoa học sẽ đáp ứng nhu cầu của xã hội cũng như đòi hỏi từ nền kinh tế thị trường và yêu cầu hội nhập quốc tế. Quá trình tự chủ của các tổ chức khoa học đòi hỏi thực hiện liên kết giữa hoạt động khoa học với đào tạo và sản xuất, ở chiều ngược lại liên 
kết này sẽ thúc đẩy quá trình tự chủ của tổ chức khoa học.

Quá trình xây dựng mô hình liên kết nghiên cứu khoa học với hoạt động sản xuất và đào tạo theo hướng tự chủ, tự chịu trách nhiệm ở Viện Hàn lâm đã định hình, thực hiện chủ trương "nhất thể hóa giữa khoa học và giáo dục đại học" và "nhất thể hóa giữa khoa học và sản xuất" của Bộ Chính trị Đảng Cộng sản Việt Nam đề ra từ 25 năm trước. Các Viện chuyên ngành, ngoài hoạt động nghiên cứu sẽ hoàn thiện chức năng đào tạo và sản xuất. Vì vậy, xác lập điều kiện cần và đủ để Viện Hàn lâm hình thành và hoàn thiện mô hình liên kết nghiên cứu khoa học với sản xuất và đào tạo trong thời gian tới là hết sức cần thiết.

\section{Tài liệu tham khảo}

[1] Nghị quyết 26/NQ-TW ngày 30/3/1991 của Bộ Chính trị về KH\&CN trong sự nghiệp đổi mới.
[2] Vũ Cao Đàm, Khuyến nghị về các biện pháp kích thích đổi mới công nghệ trong cơ chế quản lý kinh tế, Tuyển tập các Công trình đã công bố, Tập III, Nhà xuất bản Thế giới - 2009.

[3] Hoàng Xuân Long, Vấn đề gắn nghiên cứu khoa học với sản xuất ở Trung Quốc, Tạp chí Nghiên cứu Trung quốc, số 5 (69) - 2006.

[4] Vũ Cao Đàm, Nghịch lý và lối thoát, Bàn về triết lý KH\&GD Việt Nam, Nxb Thế giới. 2014.

[5] Mai Hà, Thiếu gắn kết giữa nghiên cứu và đào tạo: Đâu là nguyên nhân? Tạp chí Khoa học và Tổ quốc, số 6/2002.

[6] Nghị định số 54/2016/NĐ-CP ngày 14/6/2016 của Thủ tướng Chính phủ.

[7] Phạm Huy Tiến, giáo trình Tổ chức học đại cương, 2006.

[8] Phạm Tuấn Huy, Bàn về tố chất nhà lãnh đạo khoa học, Tạp chí Hoạt động khoa học, Bộ Khoa học và Công nghệ, số 9/2012.

\title{
Conditions for Formation and Development of Model Associating Scientific Research with Production and Training in Vietnam Academy of Science and Technology
}

\author{
Dao Thanh Truong, Pham Tuan Huy \\ ${ }^{1}$ VNU University of Social Sciences and Humanities, 336 Nguyen Trai, Thanh Xuan, Hanoi, Vietnam \\ ${ }^{2}$ Board of Inspection, Vietnam Academy of Science and Technology, \\ 18 Hoang Quoc Viet, Cau Giay, Hanoi, Vietnam
}

\begin{abstract}
From the early days of establishment, Vietnam Institute of Sciences (currently known as Vietnam Academy of Science and Technology) operated according to the model of the Soviet Academy of Sciences, Thus, it was separated between scientific research and production and training. Over the past 40 years, the Institute has gradually overcome this separation. Many models associating science with production and training have been made.

The development of the Academy in line with international integration, however, required necessary conditions for the formation and development of models associating scientific research with production and training. They are the macro management conditions and efforts of the Academy as well as specialized institutes.
\end{abstract}

Keywords: Conditions, association of science - production - training. 